\title{
Safety and efficacy profile of pembrolizumab in solid cancer: pooled reanalysis based on randomized controlled trials
}

This article was published in the following Dove Press journal:

Drug Design, Development and Therapy

27 September 2017

Number of times this article has been viewed

\section{Manni Wang* \\ Xuelei Ma* \\ Linghong Guo \\ Fan Xia}

State Key Laboratory of Biotherapy and Cancer Center, West China Hospital, Sichuan University, Chengdu, People's Republic of China

*These authors contributed equally to this work
Correspondence: Xuelei Ma State Key Laboratory of Biotherapy and Cancer Center, West China Hospital, Sichuan University, 37 Guoxue Alley, Chengdu 61004I, People's Republic of China

Tel +8628 85475576

Fax +862885502796

Email drmaxuelei@gmail.com
Background: The aim of the present review is to systematically evaluate the efficacy and safety of pembrolizumab by analyzing survival outcomes and at the same time, to present evidence for future clinical applications of anti-programmed cell death protein 1 (anti-PD-1) antibodies by analyzing the efficacy and safety of pembrolizumab.

Methods: A comprehensive literature search of PubMed, Medline, and Embase was performed for all relevant clinical trials. In this study, adverse events of any grades and grades $\geq 3$ were summarized and calculated for event rates. For controlled trials, odd ratios (ORs) were calculated to determine the role of pembrolizumab in adverse events. The Kaplan-Meier survival curves were extracted for hazard ratio (HR) calculation and survival outcomes were measured by progression-free survival (PFS).

Results: A total of 3,953 patients were included in safety analyses. The results indicated that the overall incidence of any treatment emergent adverse events was $74.3 \%$ (95\% confidence interval [CI]: 0.671-0.805). The efficacy analysis involving 915 patients with advanced melanoma suggested that $10 \mathrm{mg} / \mathrm{kg}$ of pembrolizumab every 3 weeks could improve patients' PFS (HR $=0.73,95 \%$ CI: $0.64-0.83$ ).

Conclusion: Pembrolizumab is a promising therapeutic option that could bring better survival outcomes but, at the same time, leads to higher frequency of some adverse events.

Keywords: pembrolizumab, safety, efficacy, meta-analysis

\section{Introduction}

Cancer is one of the most lethal health problems worldwide. ${ }^{1}$ One mechanism that prevents the initiation of effective antitumor responses in cancer microenvironment is immune evasion, which makes the treatment of advanced and refractory cancer difficult. ${ }^{2,3}$ Programmed cell death protein 1 (PD-1) is a highly expressed immune checkpoint receptor on lymphocytes and plays an important role in regulating T-cell responses to reduce damage to surrounding normal tissues. ${ }^{4,5} \mathrm{PD}-1$ is also highly expressed on intratumoral $\mathrm{T}_{\mathrm{REG}}$ cells and might enhance the immunosuppressive activity of these cells. ${ }^{6-9}$ This process requires the binding of PD-1 to its ligands, PD-L1 or PD-L2, to decrease the production of cytokines and the expression of antiapoptotic proteins, which ultimately suppresses cytotoxic T-cell functions. ${ }^{9}$ However, PD-L1 is upregulated on many cancer cells, which makes it easier for cells to escape from immune surveillance by inhibiting T-cell responses. ${ }^{10}$ For this reason, the therapy targeting at PD-1 to maintain T-cell activation is a promising area to be further explored.

Landmark studies have demonstrated the efficacy of anti-PD-1/PD-L1 therapies for patients with metastatic non-small-cell lung cancer (NSCLC), renal cell cancer, $\mathrm{BY}$
hereby accept the Terms. Non-commercial uses of the work are permitted without any further permission from Dove Medical Press Limited, provided the work is properly attributed. For permission hereby accept the Terms. Non-commercial uses of the work are permitted without any further permission from Dove Medict
for commercial use of this work, please see paragraphs 4.2 and 5 of our Terms (https://www.dovepress.com/terms.php). 
urothelial cancer, bladder cancer, colon cancer, and so on. ${ }^{11-20}$ The first antibodies against the immune checkpoint PD-1 receptors, nivolumab and pembrolizumab, have now been approved for clinical use. However, the preexisting studies only summarized data for certain types of cancers ${ }^{21,22}$ and the key factors associated with better clinical outcomes still remained unclear. In this study, we systematically evaluated the efficiency and safety of pembrolizumab in patients with tumors of different histological types, which hopefully could help present comprehensive evidence for future clinical applications of anti-PD-1 antibodies.

\section{Methods}

\section{Search strategy}

A comprehensive literature search of PubMed, Medline, and Embase was performed according to Cochrane guidelines ${ }^{23}$ for all relevant clinical trials on the safety and efficacy of pembrolizumab. The latest search was done on October 16, 2016. Keywords included pembrolizumab, safety, efficacy, and clinical trials. In order to ensure the completeness of the results, we also carried out further searches for relevant unpublished trials in the clinical trial registry. ${ }^{24}$

\section{Inclusion and exclusion criteria}

We referred to the Preferred Reporting Items for Systematic Reviews and Meta-Analyses (PRISMA) statement. The eligible criteria included 1) any phase clinical trials evaluating the efficacy and safety of pembrolizumab whether they had control groups or not; 2) patients in clinical trials had been histologically confirmed of advanced or refractory cancer; and 3) survival or adverse events were reported in the results or available for calculation.

Studies were excluded based on any of the following conditions: 1) review articles, meta-analysis, laboratory articles, or letters; 2) studies of other therapies; and 3) articles not provided with English version. When two articles involved the same medical center and patient cohort, the one with a larger sample size was selected. Two authors independently selected studies, and any disagreements were resolved by consulting a third author.

\section{Data extraction}

Data extracted from all eligible articles included 1) the basic information of studies: first author, year of publication, sample size, treatment regime, and study phase; 2) the types of adverse events of any grades and grades $\geq 3$, which were graded according to the National Cancer Institute (Washington, DC, USA) Common Toxicity Criteria, Version 3.0 ; 3) the number of patients with adverse events in treatment groups and control groups; and 4) hazard ratios (HRs) for progression-free survival (PFS) or overall survival (OS).

\section{Statistical analysis}

The safety analysis and efficacy analysis were performed on Comprehensive Meta-Analysis program 2 (Biostat, Englewood, NJ, USA) and Review Manager 5.2 (The Cochrane Collaboration, Copenhagen, Sweden), respectively. For single-arm studies, we calculated the proportion and the corresponding 95\% confidence intervals (CIs) of major adverse events (AEs) (both all grades and grade $\geq 3$ ). For controlled trials, the odds ratio (OR) was calculated to determine the role of pembrolizumab in adverse events' occurrence. A random-effect model (Der Simonian and Laird method) was applied if heterogeneity was observed $(P<0.10$ or $I^{2}>50 \%$ ), otherwise the fixed-effect model was used. ${ }^{25}$ All $P$-values were two sided, and a $P$-value of $<0.10$ was considered to be statistically significant.

\section{Results}

\section{Literature search results}

A total number of 51 potentially relevant articles were returned from initial search of PubMed, Medline, and Embase on October 16, 2016, and 47 articles were obtained after the removal of duplicates. After title and abstract screening, 27 articles were excluded as they were review articles, case reports, meta-analysis, animal experiments, or not in English. We then went through full-text screening of the remaining articles. Eight articles were excluded for their concentration on the safety and efficacy of other drugs, and one study about Hodgkin's lymphoma was also excluded because our analysis was based on solid tumors only. Eleven eligible studies ${ }^{11,17,26-34}$ were ultimately enrolled. Studies of the same first authors but with different study designs were enrolled. The flow diagram of the study selection process is provided in Figure 1.

\section{Study characteristics}

Eligible articles included five Phase I, four Phase II, and two Phase III randomized controlled trials or, in another classification, eight single-arm studies and three control-arm studies. Enrolled malignancies were melanoma (six trials), NSCLC (two trials), nonspecific tumors (two trials), and Merkel cell carcinoma (one trial). The baseline characteristics of the 11 included articles are presented in Table 1.

As for single-arm trials, we calculated the incidence of adverse events. As for control-arm studies, two studies with the same treatment regime in treatment groups and analyses of the same cancer type were enrolled in survival meta-analysis 


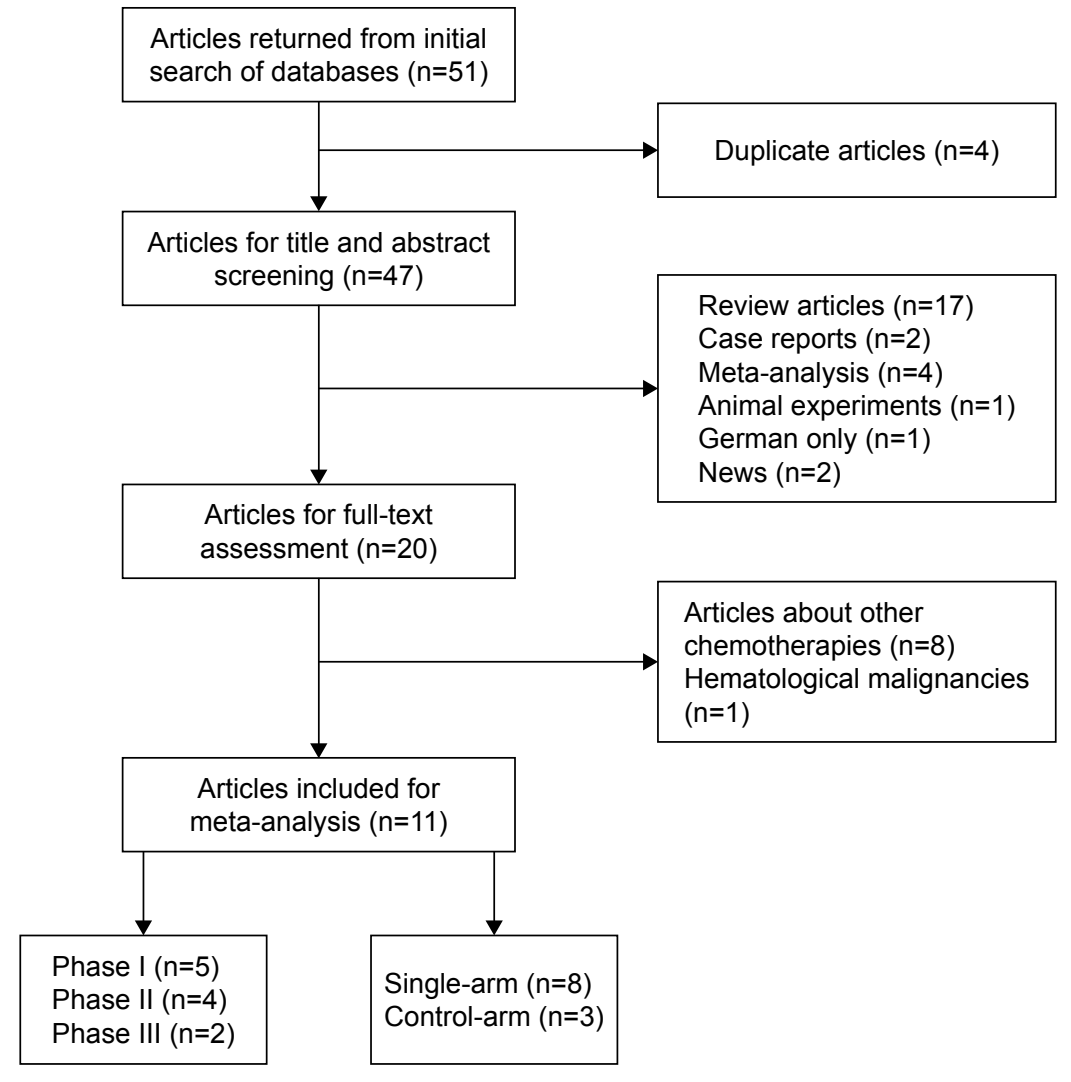

Figure I The flow diagram of the study selection process.

Table I Basic information of eligible articles

\begin{tabular}{|c|c|c|c|c|c|}
\hline Reference & Year & Phase & $\begin{array}{l}\text { Sample } \\
\text { size }\end{array}$ & Histology & Treatment \\
\hline $\begin{array}{l}\text { Garon } \\
\text { et al" }\end{array}$ & 2015 & I & 495 & $\begin{array}{l}\text { Advanced non- } \\
\text { small-cell lung } \\
\text { cancer }\end{array}$ & Pembrolizumab \\
\hline $\begin{array}{l}\text { Herbst } \\
\text { et } \mathrm{al}^{26}\end{array}$ & 2015 & II, III & 1,034 & $\begin{array}{l}\text { Advanced non- } \\
\text { small-cell lung } \\
\text { cancer }\end{array}$ & $\begin{array}{l}\text { Pembrolizumab } \\
\text { and control } \\
\text { therapy }\end{array}$ \\
\hline Hua et $\mathrm{al}^{27}$ & 2016 & I & 67 & Melanoma & Pembrolizumab \\
\hline Le et $\mathrm{a}^{17}$ & 2015 & II & 41 & $\begin{array}{l}\text { Metastatic } \\
\text { carcinoma }\end{array}$ & Pembrolizumab \\
\hline $\begin{array}{l}\text { Nghiem } \\
\text { et } \mathrm{al}^{29}\end{array}$ & 2016 & II & 26 & $\begin{array}{l}\text { Merkel cell } \\
\text { carcinoma }\end{array}$ & Pembrolizumab \\
\hline $\begin{array}{l}\text { Patnaik } \\
\text { et al }{ }^{30}\end{array}$ & 2015 & I & 32 & Solid tumors & Pembrolizumab \\
\hline Ribas et $\mathrm{al}^{31}$ & 2016 & I & 655 & $\begin{array}{l}\text { Advanced } \\
\text { melanoma }\end{array}$ & Pembrolizumab \\
\hline Ribas et $\mathrm{al}^{32}$ & 2015 & II & 540 & $\begin{array}{l}\text { Ipilimumab- } \\
\text { refractory } \\
\text { melanoma }\end{array}$ & $\begin{array}{l}\text { Pembrolizumab } \\
\text { and control } \\
\text { therapy }\end{array}$ \\
\hline $\begin{array}{l}\text { Robert } \\
\text { et } \mathrm{al}^{33}\end{array}$ & 2014 & I & 173 & $\begin{array}{l}\text { Ipilimumab- } \\
\text { refractory } \\
\text { melanoma }\end{array}$ & Pembrolizumab \\
\hline $\begin{array}{l}\text { Robert } \\
\text { et al }{ }^{34}\end{array}$ & 2015 & III & 834 & $\begin{array}{l}\text { Advanced } \\
\text { melanoma }\end{array}$ & $\begin{array}{l}\text { Pembrolizumab } \\
\text { and control } \\
\text { therapy }\end{array}$ \\
\hline $\begin{array}{l}\text { Karydis } \\
\text { et } \mathrm{al}^{28}\end{array}$ & 2016 & NA & 25 & $\begin{array}{l}\text { Uveal } \\
\text { melanoma }\end{array}$ & Pembrolizumab \\
\hline
\end{tabular}

Abbreviation: NA, not applicable. to test the efficacy of pembrolizumab. Ribas et a ${ }^{32}$ set melanoma patients into two groups (pembrolizumab at a dose of 2 or $10 \mathrm{mg} / \mathrm{kg}$ every 3 weeks versus investigator-choice chemotherapy). Similarly, Robert et $\mathrm{al}^{34}$ made comparison between pembrolizumab at a dose of $10 \mathrm{mg} / \mathrm{kg}$ every 2 or 3 weeks and control therapy to determine the contribution of pembrolizumab in adverse events.

\section{Safety analysis Overall analysis}

A total number of 3,922 patients were included in the analysis. After investigating all grades and grade $\geq 3$ adverse events, we found that the most frequently occurred events included rash, pruritus, diarrhea, nausea, myalgia, arthralgia, and pneumonitis. The pooled estimate for overall incidence of any treatment emergent adverse events (TEAEs) was $74.3 \%$ (95\% CI: 0.671-0.805) (Figure 2).

\section{Individual analysis}

In single-arm trials, no significant heterogeneity was found in some of all-grade AEs, so the fixed-effects model was applied (Figure 3A). Among them, dry mouth occurred in 10.0\% (95\% CI: $0.045-0.206)$ of participants and 9.8\% (95\% CI: $0.087-0.111$ ) of patients were observed with decreased 


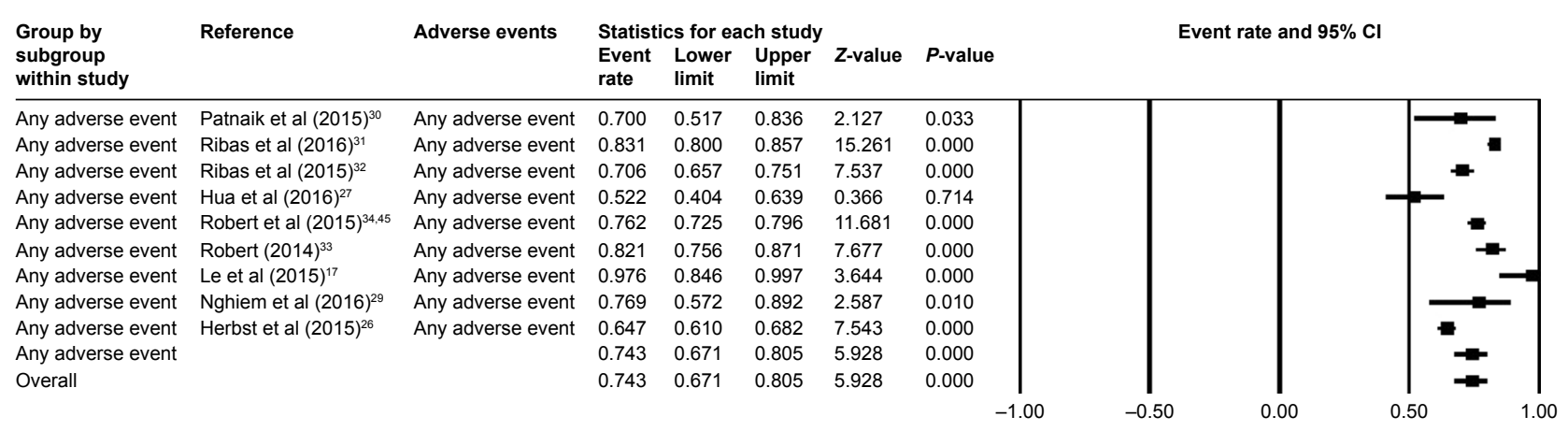

Figure 2 The pooled estimate for overall incidence of any adverse events.

Abbreviation: $\mathrm{Cl}$, confidence interval.

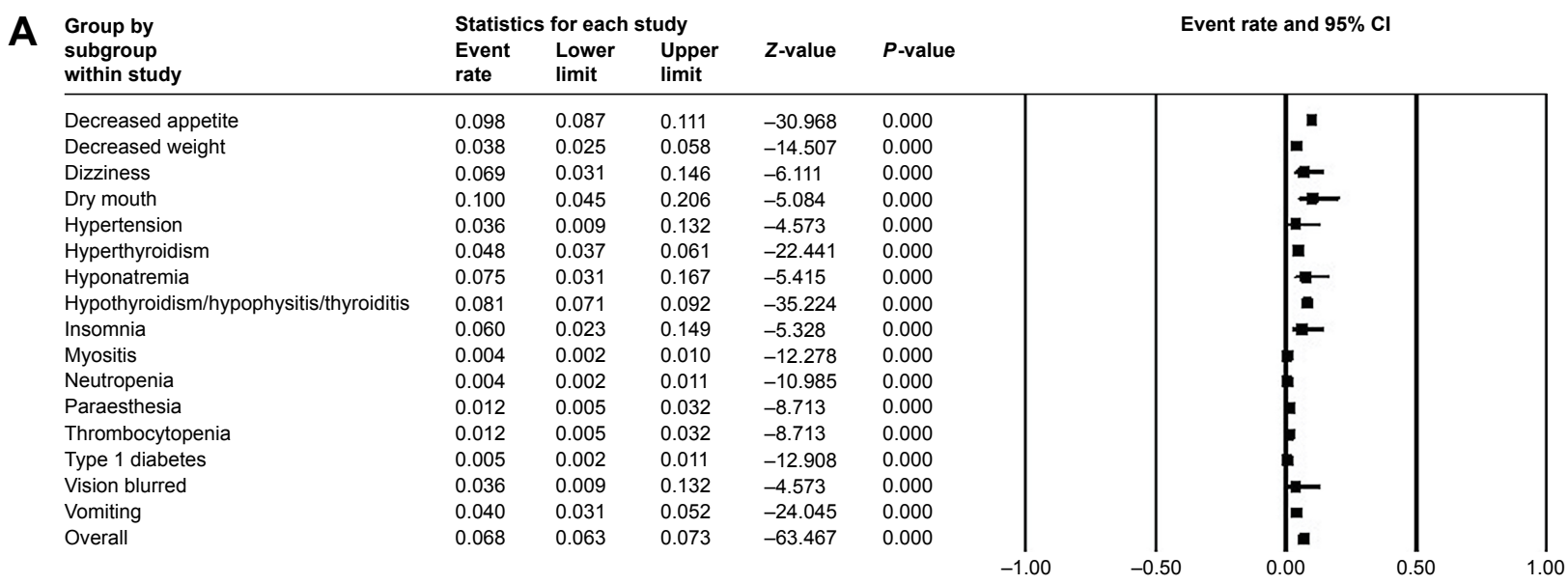

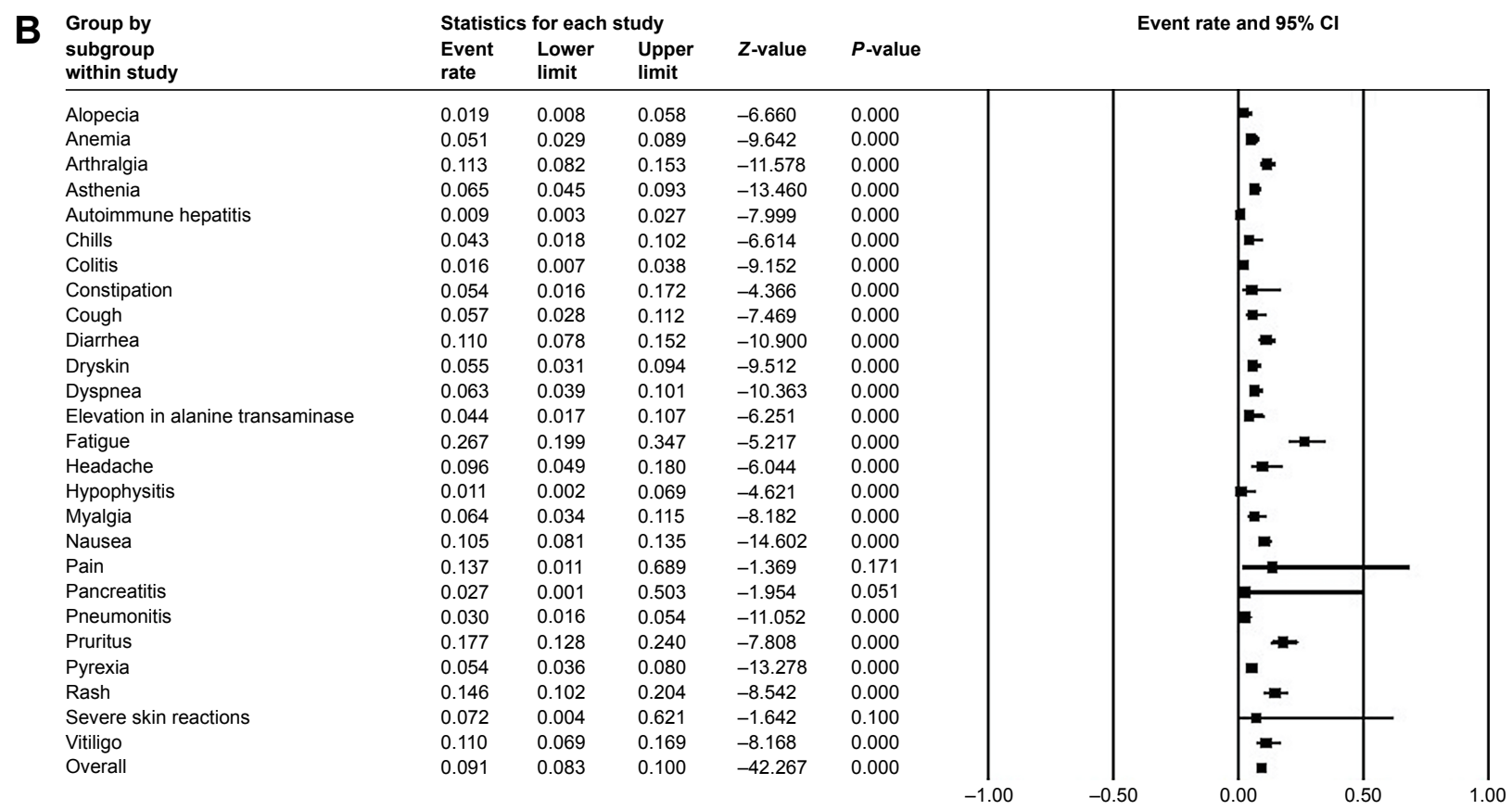

Figure 3 Forest plot of all-grade adverse events in single-arm trials.

Notes: (A) The all-grade adverse event rates and $95 \% \mathrm{Cls}$ using a fixed-effects model. (B) The all-grade adverse event rates and $95 \% \mathrm{Cls}$ using a random-effects model. Abbreviation: $\mathrm{Cl}$, confidence interval. 
appetite. Other AEs of which $I^{2}>50$ were analyzed with the random-effects model (Figure 3B). Rash (14.8\%, 95\% CI: 0.102-0.204), pain (13.7\%, 95\% CI: 0.011-0.689), pruritus (17.7\%, 95\% CI: 0.128-0.240), arthralgia (11.3\%, 95\% CI: $0.082-0.153)$, and vitiligo (11.0\%, 95\% CI: 0.089-0.169) were common in random-effects model. By comparison, severe events (grade $\geq 3$ ) were rare. The most frequently presented grade $\geq 3$ TEAEs were hyponatremia $(7.5 \%, 95 \%$ CI: $0.031-0.167$, fixed model) (Figure 4A) and elevation in alanine transaminase $(2.6 \%, 95 \% \mathrm{CI}$ : 0.006-0.101, random model) (Figure 4B).

For three control-arm studies, fixed model was applied in all-grade anemia, arthralgia, autoimmune hepatitis, and so on, with OR values (Figure 5A) while random model was used in all-grade alopecia, asthenia, colitis, and so on (Figure 5B). Of all the adverse events mentioned earlier, the most frequently occurred events included pruritus (OR $=1.899,95 \%$ CI: $0.125-8.769)$ and $\operatorname{rash}(\mathrm{OR}=1.751,95 \% \mathrm{CI}: 0.863-3.551)$. The frequency of hypothyroidism/hypophysitis/thyroiditis was significantly higher in patients treated with control therapy $(\mathrm{OR}=8.811,95 \% \mathrm{CI}: 1.340-7.929)$. Vitiligo of all grades also occurred significantly more often in the pembrolizumab cohort (OR $=6.206,95 \%$ CI: 2.677-14.388). Similar trends were observed for event rates of hyperthyroidism $(\mathrm{OR}=2.906,95 \% \mathrm{CI}: 1.419-5.951)$, pneumonitis $(\mathrm{OR}=2.458$, 95\% CI: $1.086-5.562)$, and arthralgia (OR $=1.788,95 \% \mathrm{CI}$ : 1.098-2.912). Pembrolizumab might have a dominant effect on vitiligo with the highest OR value. Similarly, grade $\geq 3$ adverse events were relatively rare and none demonstrated statistically significant ORs (Figure 6A and B). Autoimmune hepatitis ( $\mathrm{OR}=2.764,95 \% \mathrm{CI}: 0.482-15.859)$ and pneumonitis $(\mathrm{OR}=2.085,95 \% \mathrm{CI}: 0.562-7.736)$ contained 1.0 in their $95 \%$ CIs. We were, therefore, unable to determine the effect of pembrolizumab on these events.

\section{Efficacy analysis}

Five single-arm trials reported median survival time or survival rates in patients with different types of tumors, demonstrating the antitumor effect of pembrolizumab to some degree without comparison with control groups (Table 2).

\begin{tabular}{|c|}
\hline $\begin{array}{l}\text { Group by } \\
\text { subgroup } \\
\text { within study }\end{array}$ \\
\hline $\begin{array}{l}\text { Arthralgia } \\
\text { Asthenia }\end{array}$ \\
\hline Decreased appetite \\
\hline Encephalopathy \\
\hline Fatigue \\
\hline Hyponatremia \\
\hline Hypothyroidism/hypophysitis/thyroiditis \\
\hline Maculopapular rash \\
\hline Myalgia \\
\hline Nausea \\
\hline Pancreatitis \\
\hline Pyrexia \\
\hline Rash \\
\hline Type 1 diabetes \\
\hline Vomiting \\
\hline Overall \\
\hline
\end{tabular}

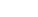

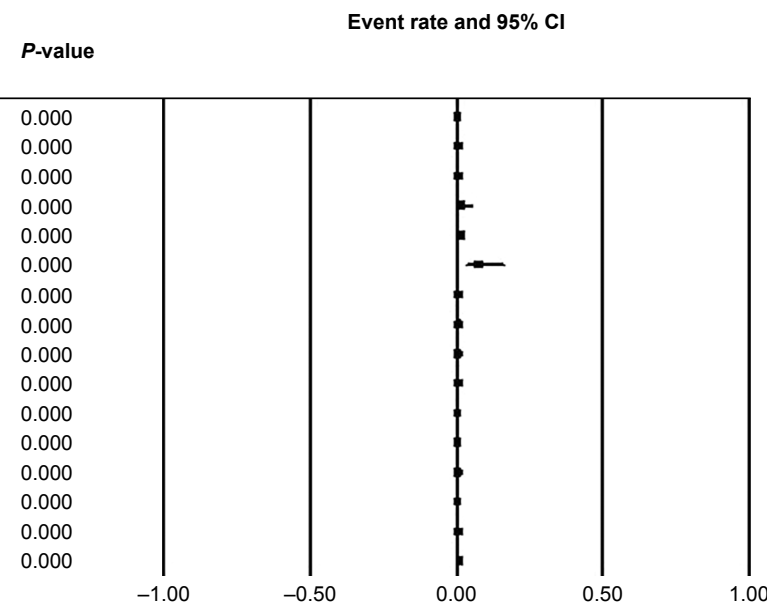

\begin{tabular}{|c|}
\hline $\begin{array}{l}\text { Group by } \\
\text { subgroup } \\
\text { within study }\end{array}$ \\
\hline Anemia \\
\hline Autoimmune hepatit \\
\hline Colitis \\
\hline Diarrhea \\
\hline Dyspnea \\
\hline Elevation in ALT \\
\hline Hypophysitis \\
\hline Pneumonitis \\
\hline Pruritus \\
\hline
\end{tabular}

Overall

\begin{tabular}{lll}
$\begin{array}{l}\text { Statistics for each study } \\
\text { Event } \\
\text { rate }\end{array}$ & $\begin{array}{l}\text { Lower } \\
\text { limit }\end{array}$ & $\begin{array}{l}\text { Upp } \\
\text { limit }\end{array}$ \\
\hline 0.004 & 0.002 & 0.009 \\
0.006 & 0.004 & 0.010 \\
0.007 & 0.004 & 0.011 \\
0.015 & 0.004 & 0.057 \\
0.015 & 0.011 & 0.021 \\
0.075 & 0.031 & 0.167 \\
0.004 & 0.002 & 0.011 \\
0.006 & 0.002 & 0.017 \\
0.006 & 0.002 & 0.017 \\
0.005 & 0.003 & 0.008 \\
0.004 & 0.001 & 0.011 \\
0.004 & 0.002 & 0.011 \\
0.006 & 0.003 & 0.011 \\
0.003 & 0.001 & 0.009 \\
0.005 & 0.003 & 0.011 \\
0.008 & 0.007 & 0.009 \\
& &
\end{tabular}

limit
0.009
0.010
0.011
0.057
0.021
0.167
0.011
0.017
0.017
0.008
0.011
0.011
0.011
0.009
0.011
0.009

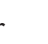

.

(a)

(n)






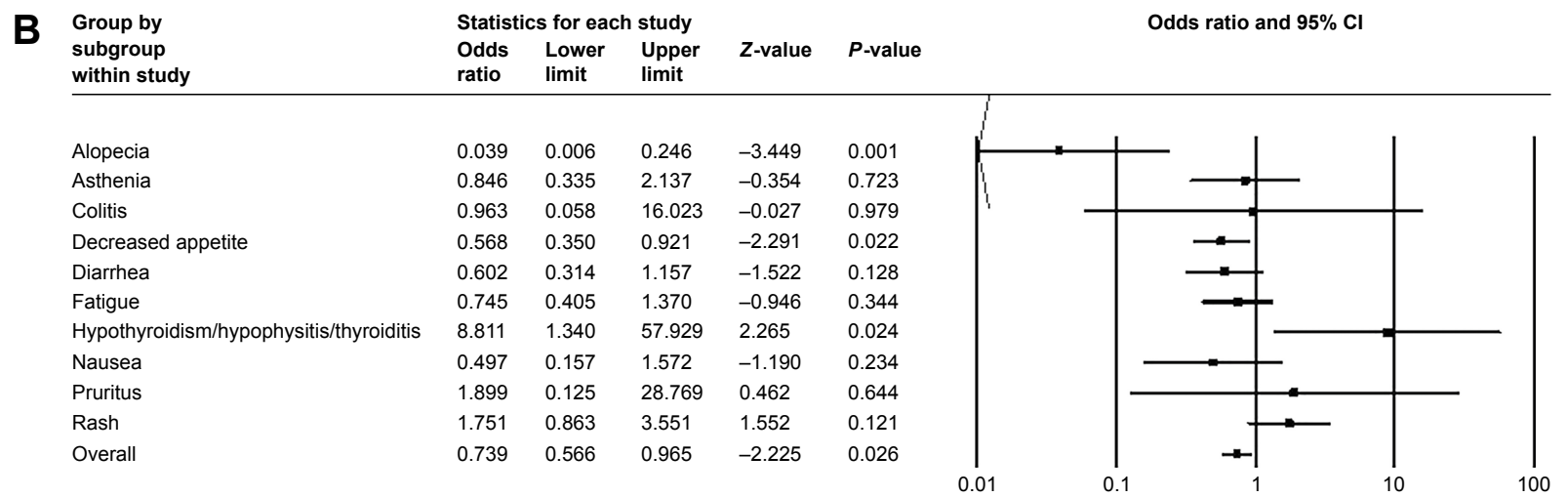

Figure 5 Forest plot of all-grade adverse events in control-arm trials.

Notes: (A) The all-grade adverse event rates and $95 \% \mathrm{Cls}$ using a fixed-effects model. (B) The all-grade adverse event rates and $95 \% \mathrm{Cls}$ using a random-effects model. Abbreviation: $\mathrm{Cl}$, confidence interval.

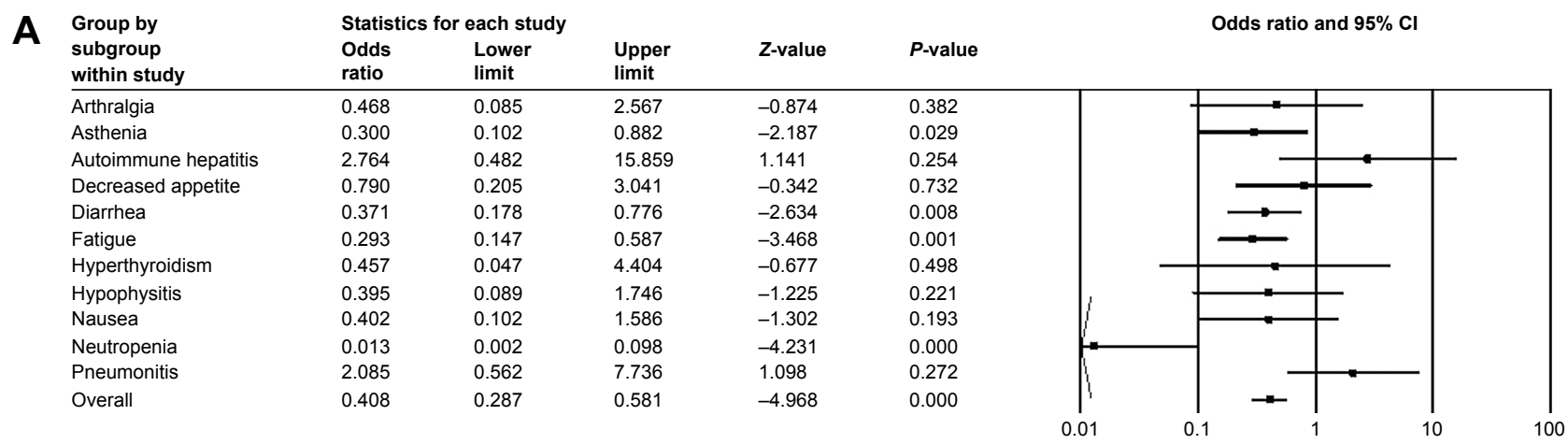

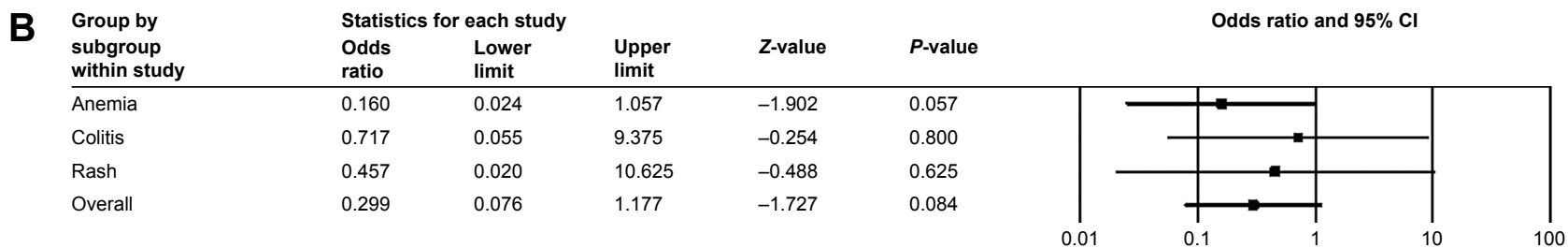

Figure 6 Forest plot of grade $\geq 3$ adverse events in control-arm trials.

Notes: (A) The grade $\geq 3$ adverse event rates and $95 \%$ Cls using a fixed-effects model. (B) The grade $\geq 3$ adverse event rates and $95 \%$ Cls using a random-effects model. Abbreviation: $\mathrm{Cl}$, confidence interval. 
Table 2 Five single-arm trials demonstrating the efficacy of pembrolizumab without comparison with control groups

\begin{tabular}{|c|c|c|c|}
\hline Reference & Tumor & Survival information & Treatment regime \\
\hline Garon et al" & Advanced NSCLC & The median duration of PFS 3.7 months, OS 12.0 months & Pembrolizumab only \\
\hline Nghiem et $\mathrm{al}^{29}$ & Merkel cell carcinoma & The rate of PFS at 6 months was $67 \%(95 \% \mathrm{Cl}, 49 \%-86 \%)$ & Pembrolizumab only \\
\hline Ribas et $\mathrm{al}^{31}$ & Advanced melanoma & $\begin{array}{l}\text { I2-month PFS rate of } 35 \%(95 \% \mathrm{Cl}, 31 \%-39 \%) \text { and } 24 \text {-month } \\
\text { OS rate of } 49 \%(95 \% \mathrm{Cl}, 44 \%-53 \%)\end{array}$ & Pembrolizumab only \\
\hline Robert et $\mathrm{al}^{33}$ & Advanced melanoma & $\begin{array}{l}\text { Median PFS was } 31 \text { weeks in the } 2 \mathrm{mg} / \mathrm{kg} \text { group and } \\
35 \text { weeks in the } 10 \mathrm{mg} / \mathrm{kg} \text { group }\end{array}$ & Pembrolizumab only \\
\hline Karydis et $\mathrm{al}^{28}$ & Uveal melanoma & Median PFS was 91 days after a median follow-up of 225 days & Pembrolizumab only \\
\hline
\end{tabular}

Abbreviations: $\mathrm{Cl}$, confidence interval; NSCLC, non-small-cell lung cancer; OS, overall survival; PFS, progression-free survival.

The efficacy of pembrolizumab was analyzed with two controlled trials, which investigated the PFS of 915 patients with advanced melanoma. All patients in treatment groups were treated with pembrolizumab $10 \mathrm{mg} / \mathrm{kg}$ every 3 weeks, and we chose 12 months as the endpoint of their survival outcome observations. Robert et $\mathrm{al}^{34}$ reported that the estimated median PFS of patients receiving pembrolizumab was 4.1 months (95\% CI: $2.9-6.9)$ and the HR was 0.58 (95\% CI: $0.47-0.72 ; P<0.001)$ for pembrolizumab compared to the control therapy. Meanwhile, the study of Ribas et al ${ }^{32}$ showed significant improvement in PFS, with an HR of 0.50 (95\% CI: $0.39-0.64)$ for $10 \mathrm{mg} / \mathrm{kg}$ compared to traditional chemotherapy $(P<0.0001)$. In addition, this effect was likely to be dose dependent, as they observed that, with the same frequency of administration, HR for pembrolizumab $10 \mathrm{mg} / \mathrm{kg}$ compared to $2 \mathrm{mg} / \mathrm{kg}$ was 0.91 (95\% CI: 0.71-1.16). Overall, in comparison with control groups, both high and low doses of pembrolizumab exhibited improvement in patients' PFS.

We then carried out meta-analysis based on these two articles. No significant heterogeneity was detected in the comparisons so the fixed-effects model was used $(P<0.00001$; $I^{2}=0$ ). Our exploratory subgroup analyses showed that $10 \mathrm{mg} / \mathrm{kg}$ of pembrolizumab every 3 weeks could improve patients' PFS (HR $=0.73,95 \%$ CI: 0.64-0.83) (Figure 7). Further large-scale studies are still expected to assess the PFS of patients with other types of cancer.

\section{Discussion}

The remarkable benefits brought by PD-1 agents pembrolizumab and nivolumab in terms of PFS and OS had been well described, and pembrolizumab has now been considered as front-line therapy in melanoma. ${ }^{35}$ However, the high cost of these agents should also be taken into consideration. According to the report by Tartari et al, ${ }^{36}$ the estimated costs associated with the use of pembrolizumab in patients with melanoma and NSCLC were 145,010 \$ and 130,511 \$ respectively, accounting for the highest per patient costs. Therefore, in order to establish more practical and beneficial clinical strategies, for the first time, we provided in our study the efficacy and safety analysis of pembrolizumab in patients with cancers of different histological types, by analyzing the largest sample size we could reach, and thus offered the most robust summary up to date of adverse events both in pembrolizumab administration groups and control groups.

There are several factors to take into account regarding the addition of pembrolizumab into traditional therapies. First, the genetic mutation was an important factor associated with AEs since the working mechanism of pembrolizumab was based on the interaction between anti-PD-1 antibodies and PD-1. ${ }^{3}$ Snyder et $\mathrm{l}^{37}$ found that a higher mutational load was related to better survival in patients receiving PD-1 blockade therapy against cutaneous melanoma. Similar results were observed in patients with metastatic melanoma by George et al. ${ }^{47}$ Meanwhile, Zhang et al ${ }^{38}$ verified the

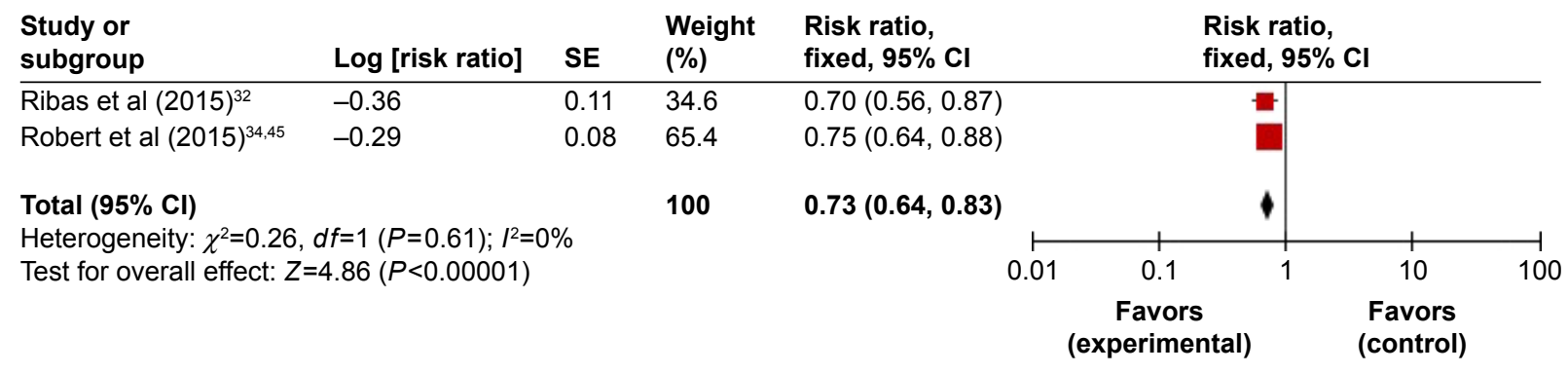

Figure 7 The hazard ratios of adverse events in a pembrolizumab treatment group compared to control therapy groups. Abbreviations: $\mathrm{Cl}$, confidence interval; SE, standard error. 
hypothesis that PD-L1 expression and smoking history were correlated with improved clinical outcomes of anti-PD-1/ PD-L1 therapies. Additionally, one potential mechanism of responses to $\mathrm{PD}-1$ inhibition might be related to the specific tumor microenvironment. Tumeh et $\mathrm{al}^{39}$ discovered that patients with higher densities of CD8-positive T cells and higher expression of the T-cell receptors in tumor microenvironment were more likely to present objective responses. However, PD-1 expression on T cells serves as a symbol for T-cell exhaustion, consistent with the observation that the function of tumor-infiltrating lymphocytes expressing PD-1 has been largely reduced. ${ }^{40}$ Another factor might be the existence of other inhibitory receptors, such as LAG3, TIM3, BTLA, CD160, and CD244. 5,13 As a result, blocking PD-1 alone might not be able to fully realize the antitumor function of $\mathrm{T}$ cells.

Our study provided information about 3,953 patients from preexisting clinical trials to investigate the increasing risk for the potential adverse events. All-grade rash (14.8\%, 95\% CI: 0.102-0.204), pain (13.7\%, 95\% CI: 0.011-0.689), pruritus (17.7\%, 95\% CI: $0.128-0.240)$, vitiligo (11.0\%, 95\% CI: 0.089-0.169), arthralgia (11.3\%, 95\% CI: 0.082-0.154), and dry mouth $10.0 \%$ (95\% CI: $0.045-0.206)$ could happen in patients treated with pembrolizumab-based therapies, while severe event (grade $\geq 3$ ) rates of rash, pruritus, and arthralgia decreased down to $0.6,1.0$, and $0.4 \%$, respectively. Similarly, control-arm analysis revealed that immune-mediated adverse events mainly affected the skin, musculoskeletal, endocrine, and gastrointestinal systems, including rash, diarrhea, myalgia, and pneumonitis. As for control-arm study, significantly higher risks of all-grade events were observed in pembrolizumab cohort. Thyroid dysfunction was the most common event and was manageable with thyroid hormone replacement therapy. The underlying mechanism of thyroid dysfunction was further unraveled by de Filette et al, by measuring thyroid autoantibodies and analyzing 18F-fluorodeoxyglucose (18FDG)-positron emission tomography/computed tomography imaging. It was suggested that thyroid autoantibodies were present in nearly half of the patients with thyroid dysfunction and, at the same time, increasing 18FDG uptake in the thyroid gland was found in all patients suspected of pembrolizumab-associated thyroiditis. ${ }^{41}$ However, none of the ORs for severe grade adverse events appeared to be statistically significant, which was consistent with results of previous safety meta-analyses. ${ }^{12,42}$

We found that the most common events of pembrolizumab therapy were cutaneous adverse effects including rash $(14.8 \%)$, pruritus $(17.7 \%)$, and less frequently vitiligo
(11.0\%). These adverse effects were generally manageable and did not require discontinuation of therapy. ${ }^{43}$ The exact mechanism of these cutaneous eruptions had not been completely elucidated. The histological findings of Shi et $\mathrm{al}^{44}$ were consistent among two anti-PD-1 agents, nivolumab and pembrolizumab, indicating that the cutaneous reaction might be a targeted effect of the PD-1/PD-L1 pathway rather than a nonspecific hypersensitivity reaction. An alternative explanation was that the administration of anti-PD-1 drug might stimulate immune response to medication that was previously tolerated.

The efficacy analysis was conducted with two controlled trials including 915 patients, of which the treatment group (pembrolizumab $10 \mathrm{mg} / \mathrm{kg}$ every 3 weeks) had presented improved PFS (HR =0.73, 95\% CI: 0.64-0.83). Similar HRs were observed for PFS in each of the two trials, a finding that reinforces the superiority of pembrolizumab over control therapy. Two recent studies have reported an improvement in OS in patients with BRAFV600 wild-type melanoma receiving nivolumab (another PD-1 blockade therapy) compared to chemotherapy. ${ }^{45}$ Combined with this finding, our pooled analysis confirmed the remarkable effect of anti-PD-1 therapy on the survival of patients with advanced melanoma. However, given the relatively small number of articles, the evaluation of this effect demanded further research.

To the best of our knowledge, our study is the most up-todate meta-analysis to assess the efficacy and safety of pembrolizumab in patients with tumors of different histological types including melanoma, NSCLC, Merkel cell carcinoma, and other solid tumors, which hopefully would be applied in future anti-PD-1/PD-L1 immunotherapy practice. PD-1 checkpoint inhibitors are currently under rapid development. Pembrolizumab is one of the earliest US Food and Drug Administration-approved PD-1 checkpoint inhibitors. It is a new, innovative paradigm and has been confirmed of its merits in improving patients' survival with less toxicity. ${ }^{46}$ All the included clinical trials were published in the last 2 years, reflecting the popularity of pembrolizumab. Furthermore, in order to avoid selective reporting bias and the incompleteness of included trials, we reviewed all the materials (including supplementary data and relevant publications mentioned). Most included articles were multicentre, international (Australia, Canada, France, and the USA), randomized clinical trials, which offers great credibility in future application.

However, some details of our study need to be further refined. Pembrolizumab is a relatively new kind of drug, which leads to the insufficiency of clinical trials for pooled safety analysis. For the same reason, publication bias and 
sensitivity analyses were not performed. High levels of heterogeneity existed in several adverse events, which might be the result of the heterogeneity of patients' profiles and treatment backgrounds. Finally, included trials failed to separate outcomes by patients' characteristics. We were therefore unable to detect the potential correlation between survival and patients' gender, age, or pembrolizumab dosages by subgroup analyses.

\section{Conclusion}

Pembrolizumab is a promising therapeutic option and was shown, in our analysis, to cause higher frequency of some adverse events. The questions addressed in this meta-analysis could currently not be answered with preexisting data. Future studies, therefore, are needed to draw definitive conclusions about the efficacy and safety of pembrolizumab, which could in turn help inform decision-making in clinical practice.

\section{Disclosure}

The authors report no conflicts of interest in this work.

\section{References}

1. Siegel RL, Miller KD, Jemal A. Cancer statistics, 2015. CA Cancer J Clin. 2015;65(1):5-29.

2. Hanahan D, Weinberg RA. Hallmarks of cancer: the next generation. Cell. 2011;144:646-674.

3. Mellman I, Coukos G, Dranoff G. Cancer immunotherapy comes of age. Nat Clin Pract Oncol. 2011;2:480-489.

4. Nishimura H, Nose M, Hiai H, Minato N, Honjo T. Development of lupus-like autoimmune diseases by disruption of the PD-1 gene encoding an ITIM motif-carrying immunoreceptor. Immunity. 1999;11:141.

5. Pardoll DM. The blockade of immune checkpoints in cancer immunotherapy. Nat Rev Cancer. 2012;12:252.

6. Francisco LM, Sage PT, Sharpe AH. The PD-1 pathway in tolerance and autoimmunity. Immunol Rev. 2010;236:219-242.

7. Okazaki T, Chikuma S, Iwai Y, Fagarasan S, Honjo T. A rheostat for immune responses: the unique properties of PD-1 and their advantages for clinical application. Nat Immunol. 2013;14:1212-1218.

8. Fife BT, Pauken KE, Eagar TN, et al. Interactions between PD-1 and PD-L1 promote tolerance by blocking the TCR-induced stop signal. Nat Immunol. 2009;10(11):1185-1192.

9. Freeman GJ, Pauken KE, Eagar TN, et al. Engagement of the PD-1 immunoinhibitory receptor by a novel B7 family member leads to negative regulation of lymphocyte activation. $J$ Exp Med. 2000;192: $1027-1034$.

10. Dong H, Strome SE, Salomao DR, et al. Tumor-associated B7-H1 promotes T-cell apoptosis: a potential mechanism of immune evasion. Nat Med. 2002;8(8):793-800.

11. Garon EB, Rizvi NA, Hui R, et al. Pembrolizumab for the treatment of non-small-cell lung cancer. N Engl J Med. 2015;372:2018-2028.

12. Gettinger SN, Horn L, Gandhi L, et al. Overall survival and long-term safety of nivolumab (anti-programmed death 1 antibody, BMS-936558, ONO-4538) in patients with previously treated advanced non-small-cell lung cancer. J Clin Oncol. 2015;33(18):2004.

13. Berger R, Rotem-Yehudar R, Slama G, et al. Phase I safety and pharmacokinetic study of CT-011, a humanized antibody interacting with PD-1, in patients with advanced hematologic malignancies. Clin Cancer Res. 2008;14(10):3044-3051.
14. Armand P, Nagler A, Weller EA, et al. Disabling immune tolerance by programmed death-1 blockade with pidilizumab after autologous hematopoietic stem-cell transplantation for diffuse large B-cell lymphoma: results of an international phase II trial. J Clin Oncol. 2011; 31(33):4199-4206.

15. Hamanishi J, Mandai M, Ikeda T, et al. Safety and antitumor activity of anti-PD-1 antibody, nivolumab, in patients with platinum-resistant ovarian cancer. J Clin Oncol. 2015;33(34):4015-4022.

16. Ansell SM, Lesokhin AM, Borrello I, et al. PD-1 blockade with nivolumab in relapsed or refractory Hodgkin's lymphoma. $N$ Engl $J$ Med. 2015;372(4):311-319.

17. Le DT, Uram JN, Wang H, et al. PD-1 blockade in tumors with mismatch-repair deficiency. Côlon Rectum. 2015;372(26):2509.

18. Motzer RJ, Rini BI, McDermott DF, et al. Nivolumab for metastatic renal cell carcinoma: results of a randomized phase II trial. J Clin Oncol. 2015;33(13):1430-1437.

19. McDermott DF, Drake CG, Sznol M, et al. Survival, durable response, and long-term safety in patients with previously treated advanced renal cell carcinoma receiving nivolumab. J Clin Oncol. 2015;33(18): 2013-2020.

20. Powles T, Eder JP, Fine GD, et al. MPDL3280A (anti-PD-L1) treatment leads to clinical activity in metastatic bladder cancer. Eur Urol. 2014;515:558-562.

21. Jia M, Feng W, Kang S, et al. Evaluation of the efficacy and safety of anti-PD-1 and anti-PD-L1 antibody in the treatment of non-small cell lung cancer (NSCLC): a meta-analysis. J Thorac Dis. 2015;7(3): 455-461.

22. Yang Y, Pang Z, Ding N, et al. The efficacy and potential predictive factors of PD-1/PD-L1 blockades in epithelial carcinoma patients: a systematic review and meta analysis. Oncotarget. 2015;7(45): 74350-74361.

23. Dai H, Qi A. Analysis of performance of reinforced concrete frame structure with staircase based on ETABS. J Earthq Eng Eng Vib. 2009; 29:136-142.

24. Richy F, Scarpignato C, Lanas A, Reginster JY. Efficacy and safety of piroxicam revisited: a global meta-analysis of randomised clinical trials. Pharmacol Res. 2009;60(4):254-263.

25. Dersimonian R, Laird N. Meta-analysis in clinical trials revisited. Contemp Clin Trials. 2015;45(pt A):139-145.

26. Herbst RS, Baas P, Kim DW, et al. Pembrolizumab versus docetaxel for previously treated, PD-L1-positive, advanced non-small-cell lung cancer (KEYNOTE-010): a randomised controlled trial. Lancet. 2015; 10:1540.

27. Hua C, Boussemart L, Mateus C, et al. Association of vitiligo with tumor response in patients with metastatic melanoma treated with Pembrolizumab. JAMA Dermatol. 2016;152(1):45-51.

28. Karydis I, Chan PY, Wheater M, Arriola E, Szlosarek PW, Ottensmeier CH. Clinical activity and safety of Pembrolizumab in ipilimumab pre-treated patients with uveal melanoma. Oncoimmunology. 2016;5(5):e1143997.

29. Nghiem PT, Bhatia S, Lipson EJ, et al. PD-1 blockade with Pembrolizumab in advanced merkel-cell carcinoma. $N$ Engl J Med. 2016; 374(26):2542-2552.

30. Patnaik A, Kang SP, Rasco D, et al. Phase I study of Pembrolizumab (MK-3475; anti-PD-1 monoclonal antibody) in patients with advanced solid tumors. Clin Cancer Res. 2015;21(19):4286-4293.

31. Ribas A, Hamid O, Daud A, et al. Association of Pembrolizumab with tumor response and survival among patients with advanced melanoma. JAMA. 2016;315(15):1600-1609.

32. Ribas A, Puzanov I, Dummer R, et al. Pembrolizumab versus investigatorchoice chemotherapy for ipilimumab-refractory melanoma (KEYNOTE002): a randomised, controlled, phase 2 trial. Lancet Oncol. 2015;16(8): 908-918.

33. Robert C, Ribas A, Wolchok JD, et al. Anti-programmed-death-receptor-1 treatment with pembrolizumab in ipilimumab-refractory advanced melanoma: a randomised dose-comparison cohort of a phase 1 trial Lancet. 2014;384(9948):1109-1117. 
34. Robert C, Schachter J, Long GV, et al; KEYNOTE-006 Investigators. Pembrolizumab versus ipilimumab in advanced melanoma. $N \mathrm{Engl}$ J Med. 2015;372(26):2521-2532.

35. Shoushtari AN, Munhoz RR, Kuk D, et al. The efficacy of anti-PD-1 agents in acral and mucosal melanoma. Cancer. 2016;122(21): 3354-3362.

36. Tartari F, Santoni M, Burattini L, Mazzanti P, Onofri A, Berardi R. Economic sustainability of anti-PD-1 agents nivolumab and Pembrolizumab in cancer patients: recent insights and future challenges. Cancer Treat Rev. 2016;48:20-24.

37. Snyder A, Makarov V, Merghoub T, et al. Genetic basis for clinical response to CTLA-4 blockade in melanoma. N Engl JMed. 2015;372:783.

38. Zhang T, Xie J, Arai S, et al. The efficacy and safety of anti-PD-1/ PD-L1 antibodies for treatment of advanced or refractory cancers: a meta-analysis. Oncotarget. 2016;7(45):73068-73079.

39. Tumeh PC, Harview CL, Yearley JH, et al. PD-1 blockade induces responses by inhibiting adaptive immune resistance. Nature. 2014; 515(7528):568-571.

40. Medina PJ, Adams VR. PD-1 pathway inhibitors: immuno-oncology agents for restoring antitumor immune responses. Pharmacotherapy. 2016;36(3):317-334.

41. de Filette J, Jansen Y, Schreuer M, et al. Incidence of thyroid-related adverse events in melanoma patients treated with Pembrolizumab. J Clin Endocrinol Metab. 2016;101(11):4431-4439.
42. Westin JR, Chu F, Zhang M, et al. Safety and activity of PD1 blockade by pidilizumab in combination with rituximab in patients with relapsed follicular lymphoma: a single group, open-label, phase 2 trial. Lancet Oncol. 2014;15(1):69-77.

43. Rizvi NA, Mazières J, Planchard D, et al. Activity and safety of nivolumab, an anti-PD-1 immune checkpoint inhibitor, for patients with advanced, refractory squamous non-small-cell lung cancer (CheckMate 063): a phase 2, single-arm trial. Lancet Oncol. 2015;16(3):257.

44. Shi VJ, Rodic N, Gettinger S, et al. Clinical and histologic features of lichenoid mucocutaneous eruptions due to anti-programmed cell death 1 and anti-programmed cell death ligand 1 immunotherapy. JAMA Dermatol. 2016;152(10):1128-1136.

45. Robert C, Long GV, Brady B, et al. Nivolumab in previously untreated melanoma without BRAF mutation - NEJM. NEngl JMed. 2015;372(4): 320-330.

46. Ramelyte E, Schindler SA, Dummer R. The safety of anti PD-1 therapeutics for the treatment of melanoma. Expert Opin Drug Saf. 2017; 16(1):41-53.

47. George S, Miao D, Demetri GD, et al. Loss of PTEN is associated with resistance to anti-PD-1 checkpoint blockade therapy in metastatic uterine leiomyosarcoma. Immunity. 2017;46(2):197-204.
Drug Design, Development and Therapy

\section{Publish your work in this journal}

Drug Design, Development and Therapy is an international, peerreviewed open-access journal that spans the spectrum of drug design and development through to clinical applications. Clinical outcomes, patient safety, and programs for the development and effective, safe, and sustained use of medicines are the features of the journal, which

\section{Dovepress}

has also been accepted for indexing on PubMed Central. The manuscript management system is completely online and includes a very quick and fair peer-review system, which is all easy to use. Visit http://www.dovepress.com/testimonials.php to read real quotes from published authors. 